\title{
Personality, prescriptivism, and pronouns: Factors influencing grammaticality judgments of gender-neutral language - CORRIGENDUM
}

\author{
EVAN D. BRADLEY, MAXWELL SCHMID AND \\ HANNAH LOMBARDO
}

https://doi.org/10.1017/S0266078419000063 Published online by Cambridge University Press, 29 March 2019

This paper was originally published erroneously omitting the names and biographical notes of two co-authors. The authors apologise for the error. The correct authorship and biographical notes are as follows:

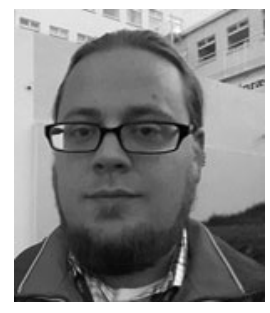

EVAN D. BRADLEY, the corresponding author, is Assistant Professor of Psychology at Penn State University, Brandywine. He earned his undergraduate degree in Cognitive Science from Northwestern University and a doctoral degree in Linguistics from the University of Delaware. His lab investigates speech and music perception (and the relationship between the two), and the psychological and social factors relevant to language learning, use, and variation. Email: evan.d. bradley@psu.edu

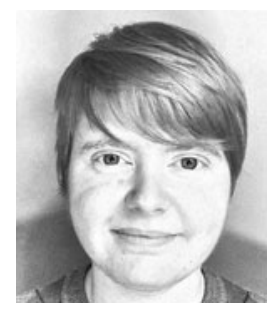

sociolinguistics, particularly sociophonetics within gender diverse communities. He enjoys interdisciplinary approaches to linguistics and collaborates with researchers from other fields such as Communication Science and Disorders.

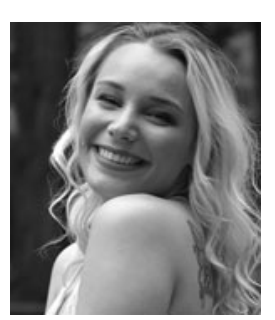

HANNAH LOMBARDO is currently pursuing a master's degree in School Psychology from Millersville University. She earned her undergraduate degree from Penn State University, Brandywine. At Penn State, Hannah conguistics and child development. ducted research on both lin-

\section{Reference}

Bradley, E., Schmid, M. \& Lombardo, H. (2019).

'Personality, prescriptivism, and pronouns: Factors influencing grammaticality judgments of gender-neutral language.' English Today, 35(4). 